\title{
Identification of QTL for barley grain size
}

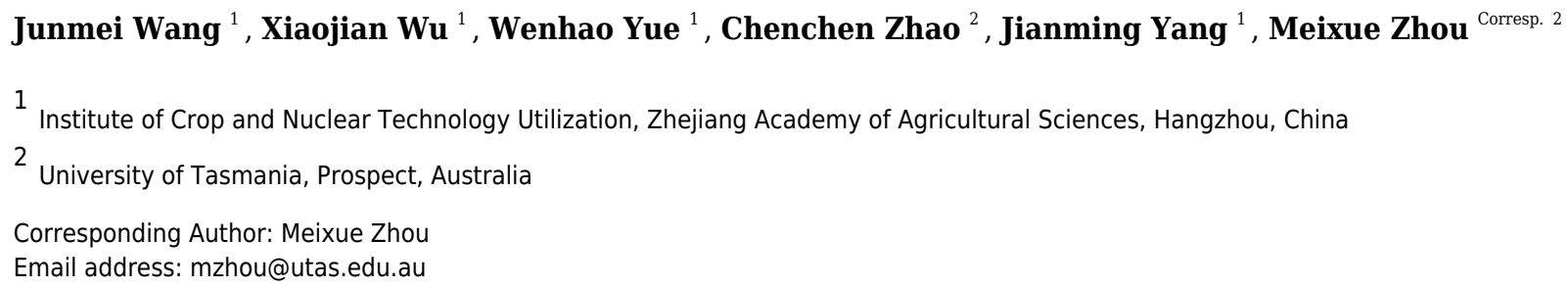

Background. Barley grain size is one of the key factors determining storage capacity during grain filling. Large, well-filled grains also have a high malt extract potential. Grain size is a complex quantitative trait and can be easily affected by environmental factors thus the identification of genes controlling the trait and the use of molecular markers linked to the genes in breeding program is the most effective way of improving grain size. Methods. Grain sizes of 188 doubled-haploid (DH) lines derived from the cross of a Japanese malting barley variety (Naso Nijo) and a Chinese feed barley variety (TX9425) were obtained from three different sites in two consecutive years. The average data were used for identifying QTL for grain size. Results. A total of four significant QTL were identified for grain length $(\mathrm{GL})$ and three for grain width (GW). The two major GL QTL are located at similar positions to the QTL for malt extract on $2 \mathrm{H}$ and uzu gene on $3 \mathrm{H}$, respectively. However, the GL QTL on $2 \mathrm{H}$ is more likely a different one from the malt extract QTL as most of the candidate genes are located outside the fine mapped QTL region for malt extract. The GL QTL on $3 \mathrm{H}$ is closely linked with uzu gene but not due to a pleiotropic effect of $u z u$. The three QTL for grain width on $1 \mathrm{H}, 2 \mathrm{H}$ and $5 \mathrm{H}$, respectively, were located at same position to those for GL. 


\section{Identification of QTL for barley grain size}

2 Junmei Wang ${ }^{1}$, Xiaojian $\mathrm{Wu}^{1}$, Wenhao Yue ${ }^{1}$, Chenchen Zhao ${ }^{2}$, Jianming Yang ${ }^{1}$, Meixue Zhou ${ }^{2}$,

$3{ }^{1}$ Institute of Crop and Nuclear Technology Utilization, Zhejiang Academy of Agricultural

4 Sciences, Hangzhou 310021, China

5 2Tasmanian Institute of Agriculture, University of Tasmania, Private Bag 1375, Prospect, TAS

67250 , Australia.

7 Corresponding author:

8 Meixue Zhou

9165 Westbury Rd, Prospect, TAS 7250, Australia

Email: meixue.zhou@utas.edu.au 


\section{Abstract}

Background. Barley grain size is one of the key factors determining storage capacity during grain filling. Large, well-filled grains also have a high malt extract potential. Grain size is a complex quantitative trait and can be easily affected by environmental factors thus the identification of genes controlling the trait and the use of molecular markers linked to the genes in breeding program is the most effective way of improving grain size.

Methods. Grain sizes of 188 doubled-haploid (DH) lines derived from the cross of a Japanese malting barley variety (Naso Nijo) and a Chinese feed barley variety (TX9425) were obtained from three different sites in two consecutive years. The average data were used for identifying QTL for grain size.

Results. A total of four significant QTL were identified for grain length (GL) and three for grain width (GW). The two major GL QTL are located at similar positions to the QTL for malt extract on $2 \mathrm{H}$ and $u z u$ gene on $3 \mathrm{H}$, respectively. However, the GL QTL on $2 \mathrm{H}$ is more likely a different one from the malt extract QTL as most of the candidate genes are located outside the fine mapped QTL region for malt extract. The GL QTL on $3 \mathrm{H}$ is closely linked with $u z u$ gene but not due to a pleiotropic effect of $u z u$. The three QTL for $\mathrm{GW}$ on $1 \mathrm{H}, 2 \mathrm{H}$ and $5 \mathrm{H}$, respectively, were located at same position to those for GL.

\section{Keywords}

Barley, grain size, quantitative trait loci, molecular marker 
32 Introduction

Barley (Hordeum vulgare L.) is considered to be the first crop domesticated by human ancestors back to 10,000 years ago (Zohary et al., 2012). It is not only an important crop model for studies on genetics, biochemistry and biology development (Giraldo et al., 2019), but is also widely used for animal feeding, malting and brewing, as well as human food (Zhou, 2010; Walker and Panozzo, 2016; Wendt et al., 2016). Barley grain yield is determined by various yield components (Benbelkacem et al., 1984; Hadjichristodoulou, 1990; Peltonen-Sainio et al., 2007). The sink capacity, a key to grain yield, is a function of the number of grains per unit land area and their potential size (Bingham et al., 2007). Barley grain size correlates with not only barley yield (Xu et al., 2018) but also grain texture, such as malting quality, starch and protein content (Walker et al., 2013; Yu et al., 2017) thus is an important end-use quality parameter (Holopainen et al., 2005; Psota et al., 2007; Mayolle et al., 2012). Enhancing grain size is, therefore, one of efficient ways of increasing yield and improving end-use efficiency of barley.

Grain size in rice has attracted more attention than that in barley, with many genes/QTL determining grain sizes having been identified. These include grain size 5, GS5, which encoding a putative serine carboxypeptidase (Li et al., 2011), $q G L 3$ and $1 G W 2 a$ (Sun et al., 2013), GL3.1, a protein from phosphatase kelch (PPKL) family which influences protein phosphorylation in the spikelet and accelerates cell division (Qi et al., 2012), and GS3 which are composed of four domains that function differently in determining grain sizes (Fan et al., 2006; Mao et al., 2010). In comparison to rice, there are only limited reports on QTL for barley grain size. From a DH population of a cross between six-rowed and two-rowed barleys, eight QTL were identified for grain length (GL) and nine for grain width (GW) (Wang et al., 2019). Among these QTL, the vrs1(HORVU2Hr1G092290) was annotated to be the candidate gene for the major QTL on $2 \mathrm{H}$ as a homeobox-Leucine Zipper Protein which controls row type and nud (HORVU7Hr lG089930) that determines the hulled/naked caryopsis morphology is more likely the candidate gene for chromosome 7H QTL hotspot region underlying grain size, though this candidate gene was annotated an ethylene-responsive transcription factor (Wang et al., 2019). Five QTL were 
identified from crosses between a wild barley and two cultivated barley cultivars with two major ones on $3 \mathrm{H}(20.7-25.6 \mathrm{cM})$ and $4 \mathrm{H}(4 \mathrm{H} 62.9-69.9 \mathrm{cM})$, respectively (Zhou et al., 2016). Eleven grain length QTL were identified from a cross between two Australian malting varieties, Vlamingh and Buloke (Walker et al., 2013) but only two major QTL for grain length (qGL2H and qGL5H) were identified from the same cross in a different study (Watt et al., 2019). qGL5H has been fine mapped to a $1.7 \mathrm{Mb}$ interval comprising of 23 candidate genes related to grain sizes (Watt et al., 2019). By employing the same material, qGL2H was fine mapped to a $140.9 \mathrm{~Kb}$ interval and a gene that encodes a MYB transcription factor is likely the candidate for this QTL (Watt et al., 2020). Genome-wide association studies (GWAS) have also been successfully used in mapping grain size related QTL in sorghum (Tao et al., 2020), rice (Ma et al., 2019) and Wild Wheat Aegilops tauschii (Arora et al., 2017).

In the current study, 188 doubled-haploid (DH) lines derived from the cross between a Japanese malting barley (Naso Nijo) and a Chinese feed barley (TX9425) were grown in eight different environments (three different sites $\times$ multiple years). Seven significant QTL for grain size were identified on $1 \mathrm{H}, 2 \mathrm{H}, 3 \mathrm{H}$ and $5 \mathrm{H}$, respectively. One of the QTL $(Q G l . N a T x-2 H)$ was located at a similar position to a previously reported malt extract QTL (Wang et al., 2015). Given that malt extract QTL were once reported to corelate with grain size (Walker et al., 2013), we analysed the QTL for grain size using malt extract as covariates. Our results suggested a close linkage between malt extract and grain size, but these two traits are controlled by different genes, which was confirmed by various near iso-genic lines, adding the novelty to our findings. Overall, the this study identified new QTL for grain sizes and investigated the relationship between grain size and major quality traits.

\section{Materials and methods}

\section{Plant materials and field experiments}

A doubled haploid $(\mathrm{DH})$ population containing 188 lines derived from the $\mathrm{F}_{1}$ of the barley cross between TX9425 (a Chinese feed barley, two-rowed) and Naso Nijo (a Japanese malting barley, two-rowed) by the anther culture method was employed for identifying QTL determining grain 
86

87

width and length. More details referring to this DH population and their parents can be found in previous studies (Wang et al., 2015). All the DH lines and parents were obtained from Tasmanian Institute of Agriculture, University of Tasmania and were grown in Hangzhou (HZ), Zhejiang province, and Yancheng, Jiangsu province (YC) in three successive growing seasons (2006/07 (06), 2007/08 (07) and 2010/11(11)), and Baoshan, Yunnan province (BS) in two continuous growing seasons (2006/07 (06) and 2007/08 (07)). HZ had a slightly higher temperature and more rainfall than $\mathrm{YC}$ and $\mathrm{BS}$ during the grain filling stage. 150 vigorous seeds of each line or variety were sown in a $2 \mathrm{~m}$ row with $0.25 \mathrm{~m}$ spacing between rows. All experiments were arranged as a randomized complete block design with three replications. All fields were cultivated with medium fertility, manually weeding and rainfall irrigated. On maturity, grains of each line or variety were harvested for target analysis.

\section{Phenotypic measurements}

At maturity, kernels of plants were bulk-harvested and sun-dried for seed morphological analysis. Grain size traits, grain length (GL, mm), and grain width (GW, mm) were manually measured. For GL estimation, 15 randomly picked kernels from the bulked kernels were lined head to toe horizontally and the total length was estimated using an electronic LCD digital calliper. For GW estimation, instead of lining seeds head to toe, 15 randomly selected seeds were lined side by side and the total length was estimated by the same calliper. The average of three replicated measurements for both grain length and width was recorded for further analysis.

\section{Statistical analysis}

Analysis of variance (ANOVA) was conducted on replicated measurements from eight sites/years using IBM SPSS statistical analysis software (Chicago, USA). Single environmental effect and combined environmental effects on GL and SW were also analysed. Best linear unbiased predictions (BLUPs) for grain size characteristics were calculated using linear mixed models for individual trials and a combined analysis of all field trials known as a multi-environment trial (MET). The simplified model is given by

$\mathrm{y}=\mathrm{X}_{\mathrm{t}}+\mathrm{Z}_{\mathrm{u}}+\mathrm{e}$ 
113 where $\mathrm{y}$ is the vector of observations for different grain size characteristics; $\mathrm{X}$ is a design matrix 114 associated with a vector of fixed effects $t ; Z$ is a design matrix associated with a vector of random 115 effects $u$; and e is the vector of residuals that include residual error variance (Smith et al. 2019).

116 Trait BLUPs were obtained using linear mixed models using advanced restricted maximum 117 likelihood techniques. The significance in seed width and seed length between high and low malt 118 extract lines was performed with student one-tail t-test.

\section{Genotype analysis}

120 Genomic DNA was extracted from the leaf tissue of three-week old seedlings, based on a modified

CTAB method described by Stein et al (Stein et al., 2001). DH lines and the two parental varieties were genotyped with DArTSeq (http://www.diversityarrays.com/dart-application-dartseq). Due to the large number of DNA markers ( 30,000 SNP and DArTSeq markers), markers with the same positions or with greater distortion and missing data were removed from the map construction. These markers were combined with previous genotypic data (DArT and SSR markers) and were employed for QTL analysis (Xu et al., 2012; Wang et al., 2015).

\section{QTL analysis}

The construction of a genetic linkage map was produced as described earlier (Wang et al., 2015).

The genetic linkage map produced from the TX9425/Naso Nijo DH population using over 2,500 markers and BLUP data of grain size from different years and sites were used for QTL analysis. The software package MapQTL6.0 (von Korff et al., 2008) was used to detect QTL which were first analysed by interval mapping (IM). The closest marker at each putative QTL identified using interval mapping was selected as a cofactor and the selected markers were used as genetic background controls in the approximate multiple QTL model (MQM). A logarithm of the odds (LOD) threshold values applied to declare the presence of a QTL were estimated by performing the genome wide permutation tests using at least 1000 permutations of the original data set for each trait, resulting in a 95\% LOD threshold of around 3.0 and the walking speed for the genomewide scan was set at $1 \mathrm{cM}$. The percentage of variance explained by each QTL $\left(\mathrm{R}^{2}\right)$ was obtained by using restricted MQM mapping. Graphical representation of linkage groups and QTL was 
carried out using MapChart 2.2 (Voorrips, 2002).

\section{Candidate gene annotation}

To identify candidate genes underlying grain size QTL, we localised the closest marker on the POPseq genetic map of Morex $\times$ Barke (Mascher et al., 2013). Barley population sequencing data were downloaded following (Mascher et al., 2013). The marker primer sequences were used to blast barley databases on http://webblast.ipk-gatersleben.de/barley/ for candidate genes. To be more accurate in candidate genes predication, cloned genes in rice which determine grain sizes were referred to investigate if any barley homolog genes were located within the identified QTL zone in this project. Since QTL zone was identified by the DArT Markers, the physical distance of the QTL zone was then determined by blasting the up and down marker sequence in a barley database (https://webblast.ipk-gatersleben.de/barley_ibsc/). Subsequently, corresponding protein sequences from cloned rice genes (https://funricegenes.github.io/) were used to blast barley homolog genes in the IPK database, where the physical location was identified and further checked with the reported QTL in this project.

\section{Results}

\section{Grain size traits for parents and $\mathrm{DH}$ lines}

We evaluated GL and GW of the DH population and the parents from multiple years/sites. The descriptive mean values of grain length and width for the parents and the double-haploid population in each environment are shown in Table 1. Naso Nijo showed higher values of GW in all environments while TX9425 had higher GL under all environments. Transgressive segregation was found with some DH lines showing higher or lower values than both parents (Table 1). The effects of genotypes, locations, and years were highly significant for the grain size traits (Table 2). For example, one parent TX and DH lines showed generally higher GL in YC11 than trials from other locations. Interactions between genotypes, locations, and years were also significant for these traits.

\section{QTL analysis for grain length (GL)}

Four significant grain length QTL (QGl.NaTx-1H, QGl.NaTx-2H, QGl.NaTx-3H and QGl.NaTx- 
167

168

169

170

171

172

173

174

175

176

177

178

179

180

181

182

183

184

185

186

187

188

189

190

191

192

193

5H) were identified using MET-BLUP data from all different environments (Fig 1, Table 3). These QTL explained $6.8-29.8 \%$ of the phenotypic variation. The total phenotypic variation explained by these six QTL was about 70\%. Naso Nijo alleles of QGl.NaTx-1H and QGl.NaTx-3H contributed to longer grain while for $Q G l . N a T x-2 H$ and $Q G l . N a T x-5 H$, TX9425 alleles contributed to longer grain (Table.3). The most significant QTL, $Q G l . N a T x-2 H$, was identified on $2 \mathrm{H}$ with the closest marker of 3256205S2. This QTL explained 29.8\% of the phenotypic variation with a LOD value of 21.95 (Fig 1, Table 3). Another major QTL QGl.NaTx-3H.1 with the closest marker of $6283018 \mathrm{~S} 3$ explained $21.9 \%$ of the phenotypic variation. These two major QTL were less affected by growing conditions and were detected in most of the trials (Table S2). The other QTL showed a significant interaction with growing conditions and only detected in some environments, four of eight for the QTL on 1H and two of eight for the QTL on 5H (Table S2).

\section{QTL analysis for grain width $(G W)$}

Three QTL ( $Q G w . N a T x-1 H, Q G w . N a T x-2 H$, and $Q G w . N a T x-5 H)$ were detected for GW based on BLUP from all environments (Table 3). QGw.NaTx-1H explained 9.5\% of the phenotypic variance, with 4170979D1 being the closest marker and Naso Nijo allele contributing greater grain width. QGw.NaTx-2H was located on $2 \mathrm{H}$ with the nearest marker of 5258068D2, explaining 17.8\% of the phenotypic variation. TX9425 contributed to the wider grain allele. QGw.NaTx-5H was located on $5 \mathrm{H}$ with the closest marker of $3273028 \mathrm{D} 5$, explaining $8.5 \%$ of the phenotypic variation. The major QTL $Q G w \cdot N a T x-2 H$ were identified in most of the environments while $Q G w \cdot N a T x-1 H$ and $Q G w \cdot N a T x-5 H$ showed significant interactions with environments, being significant in only three and two environments, respectively. All three QTL were located at similar positions to those for GL.

\section{QTL analysis for grain length using malt extract as a cofactor}

Among the identified QTL for grain size, QGl.NaTx-2H and $Q G w . N a T x-2 H$ were located to a similar position of a reported major QTL controlling malt extract using the same population (Wang et al., 2015). To confirm if these QTL are conferring to the same gene, QTL analysis for grain size was further conducted using malt extract as a covariate. By doing so, QGl.NaTx-2H.1 was still 
194

195

196

197

198

199

200

201

202

203

204

205

206

207

208

209

210

211

212

213

214

215

216

217

218

219

220

significant but the phenotypic variation determined by this QTL reduced from $29.8 \%$ to $23.0 \%$, suggesting that GL and malt extract were controlled by different but closely linked genes. Other QTL showed no significant changes in the percentage of phenotypic variation determined when using malt extract as a covariate (Table 3).

\section{QTL analysis for grain length using uzu gene as cofactor}

The QTL QGl.NaTx-3H.1 on 3H was located on a similar position of the $u z u$ gene from TX9425 (Wang et al., 2010; Li et al., 2015; Chen et al., 2016) and QTL for awn length (Chen et al., 2012). When using awn length as a covariate, phenotypic variation determined by QGl.NaTx-3H.1 slightly decreased from $21.9 \%$ to $16.1 \%$ while the percentages variation determined by other QTL were not changed (Table 3), confirming the close linkage between $u z u$ and QTL QGl.NaTx-3H.

\section{Correlations between seed size and malt extract}

To phenotypically investigate the correlation between seed size (both GL and GW) and malt extract values, we selected representative near isogenic lines (NILs) with high and low malt extract developed from the same cross to compare grain width and grain length. No significant difference in both GL or GW between high and low malt extract NILs $(\mathrm{P}>0.05)$ was found, confirming that grain size and malt extract were controlled by different genes.

\section{Candidate gene predication}

Ten genes determining rice grain size and their orthologs in barley were collected in Table S1. After comparing seven significant QTL identified in this project with rice grain size genes, three barley homolog genes (Table $\mathrm{S} 1)$, coding carboxypeptidase $(1 \mathrm{H})$, cytochrome $(5 \mathrm{H})$, mitogenactivated protein $(1 \mathrm{H})$, respectively, were identified. No rice homolog genes were identified on $2 \mathrm{H}$ and 3H QTL in this study. However, based on literature, several genes which can affect grain size are located within these QTL regions. Genes related to phytochrmones biosynthesis and cell elongation within these QTL regions were also listed as potential candidate genes (Table S1).

8 Discussion

Barley grain sizes positively associated with starch contents which contributes to process performance in human food, animal feed and brewing (Yu et al., 2017). Improving grain size is one 
of the objectives in breeding programs for not only improved quality but also high yielding (Serrago et al., 2013). Grain size is a quantitative trait controlled by multiple genes (Zhou et al., 2016) and can also be affected by the environment (Walker et al., 2013). The identification of QTL and molecular markers linked to grain size is essential for breeders to pyramid different QTL through marker assisted selection. Only a limited number of QTL for grain size have been identified with some larger effect ones on $2 \mathrm{H}, 3 \mathrm{H}, 4 \mathrm{H}$ and $5 \mathrm{H}$. In this study, we have identified four QTL for GL, and three QTL for GW. Among the four identified significant QTL for GL, QGl.NaTX-2H and QGl.NaTx-3H were less affected by environments and determined a large percentage $(29.8 \%$ and $21.9 \%$, respectively) of phenotypic variation (Table 3). A major QTL for GL have been reported on $2 \mathrm{H}$ from the cross of Vlaminh and Buloke which is located at 70-80 cM in one report (Walker et al., 2013) but at 159-179 cM in another report (Watt et al., 2019) which is further fine mapped to a 140.9 Kb interval (Watt et al., 2020). The QTL are apparently different from our major QTL on 2H for GL which was located at $10.02 \mathrm{cM}$ (Table 3). The $2 \mathrm{H}$ QTL identified in this study determined nearly $30 \%$ of the phenotypic variation with the closest marker of $32562045 \mathrm{~S} 2$ at the position of $10.02 \mathrm{cM}$. At a similar position (16.3 $-17.5 \mathrm{cM})$, a QTL was also found from a cross between a long-kernel wild barley and cultivated barley cultivars but only determined a small proportion $(10.4 \%)$ of the phenotypic variation (Zhou et al., 2016).

The other major GL QTL identified on $3 \mathrm{H}(Q G l . N a T x-3 H)$ in this study was in a similar position to $u z u$ gene which controls plant dwarfness and has a pleiotropic effect on spike morphology (Chen et al., 2016). QTL analysis using $u z u$ gene as a covariate indicated that this QTL was not the same but closely linked to $u z u$ (Table 3). This QTL has also been reported in previous studies (Ayoub et al., 2002; Zhou et al., 2016) from populations with no $u z u$ gene, confirming that the QTL was not due to a pleiotropic effect of $u z u$. The major QTL for grain size on $2 \mathrm{H}$ was not reported before, and the analysis using malt extract as covariate only suggested the linkage of malt extract and grain size, belonging to separate genes/traits that can be selected independently.

QTL alleles determining seed size also tend to determine malt quality. QTL alleles leading to increased variability of the kernel size were associated with poor malt quality (Ayoub et al., 2002). 
In our study, the QTL on $2 \mathrm{H}$ for GL $(Q G l . N a T x-2 H)$ is located at a similar position to a previously reported QTL for malt extract (QMe.NaTx-2H) (Wang et al., 2015). To investigate whether these two QTL are the same, we further applied QTL analysis for GL using malt extract as a covariate. Results suggested that these two QTL are independent, instead of a single one gene with pleotropic effect. To further confirm this, we checked several pairs of near isogenic lines (NILs) differing in malt extract QTL. No significant differences were found between lines with high malt extract and those with low malt extract (Figure 2).

Three barley ortholog genes were found within the identified QTL regions in this study through protein sequence alignment to the cloned grain size genes in rice. Within QGl.NaTx-1H, HRVU.MOREX.r2.1HG0042890 is an ortholog to OsGS5, encoding a serine carboxypeptidase and functions as a positive regulator of grain size ( $\mathrm{Li}$ et al., 2011). Another ortholog gene (HORVU.MOREX.r2.1HG0040860) of OSMAPK6 was also identified within this QTL region, encoding mitogen-activated protein kinase 6, determining rice grain size (Liu et al., 2015b). SMALL GRAIN 1 is another mitogen-activated protein kinases identified in rice, involving regulating rice grain sizes, its homolog gene HORVU.MOREX.r2.5HG0381450 was identified within $Q G l . N a T x-5 H$ and encode cytochrome, a protein involving cell wall elongation in barley (Table S1). Several candidate genes linked to cell growth and phytohormones also exist in the GL QTL region. $\mathrm{ABC}$ transporters play critical roles in plant growth and development, especially for the development of specialized plant cells (Do et al., 2018) and regulation of root cell growth (Larsen et al., 2007). MYB transcription factor is also proposed to be the candidate for GL (Watt et al., 2020). It is linked with cell growth and seed production through interacting with plant hormones, playing roles in sperm-cell, stamen development, cotton fibre and even stomatal cell divisions (Lai et al., 2005; Rotman et al., 2005; Pu et al., 2008; Zhang et al., 2010). Cytochrome P450 gene, which belongs to CYP78A subfamily, was reported to have a function in seed and fruit size development (Tian et al., 2016). Zinc finger proteins could also be good candidates for seed growth as they not only play a strong role in regulating cell growth, but also are critical for chloroplast and palisade cell development, thus affect seed filling and change seed size (Næsted 
275

276

277

278

279

280

281

282

283

284

285

286

287

288

289

290

291

292

293

294

295

296

297

298

299

et al., 2004). Manipulating ethylene signalling also indicates evidence to improve yield-related traits in crops. Overexpression of an ethylene response element MHZJ, a membrane protein, promoted grain sizes in rice (Ma et al., 2013). Similar findings were also observed in a wheat study, where overexpression of the transcriptional repressor (TaERF3, ethylene response factor), vice versa, decreased grain size and affected 1000-grain weight (Wang et al., 2020). IAA and gibberellin play critical roles in regulating seeds size, such that IAA-glucose hydrolase gene $T W G 5$ determines grain length and yield (Ishimaru et al., 2013) and the identified quantitative locus $G W 6$ controls rice grain size and yield through the gibberellin pathway (Shi et al., 2020). Based on these reported genes and their functions in determining grain sizes, we highlighted 66 genes involving the discussed functions in accordance with the identified QTL from this population. Most of those candidate genes are located outside the area for malt extract (Figure 1).

\section{Conclusions}

In this study, seven major QTL for grain size were identified. The major one on $2 \mathrm{H}$ (QGl.NaTx$2 H$ ) is closely linked to the reported QTL for malt extract (QMe.NaTx-2H, Wang et al., 2015). The other major QTL on $3 \mathrm{H}$ for GL $(Q G l . N a T x-3 H)$ shares a similar position with a reported dwarf gene, $u z u$ (Chen et al., 2016), but they are two independent genes and control different phenotypes. Therefore, these major QTL can be used in breeding program to improve grain size, independent of malting quality and plant height.

\section{Acknowledgements}

This work was supported by National Natural Science Foundation of China (31671678), the Key

Research Foundation of Science and Technology Department of Zhejiang Province of China (2016C02050-9), China Agriculture Research System (CARS-5), and Grains Research and Development Corporation (GRDC) of Australia.

References 
Ayoub, M., Symons, J., Edney, J., and Mather, E. (2002). QTLs affecting kernel size and shape in a two-rowed by six-rowed barley cross. Theoretical and Applied Genetics 105(2-3), 237247. doi: 10.1007/s00122-002-0941-1.

Arora, S., Singh, N., Kaur, S., Bains, NS., Uauy, C., Poland, J., Chhuneja, P. (2017) GenomeWide Association Study of Grain Architecture in Wild Wheat Aegilops tauschii. Frontiers in Plant Science 31 (8): 886. doi:10.3389/fpls.2017.00886.

Benbelkacem, A., Mekni, M.S., and Rasmusson, D.C. (1984). Breeding for High Tiller Number and Yield in Barley 1. Crop Science 24(5), 968-972.

Bingham, I.J., Blake, J., Foulkes, M.J., and Spink, J. (2007). Is barley yield in the UK sink limited? II. Factors affecting potential grain size. Field Crops Research 101(2), 212-220. doi: 10.1016/j.fcr.2006.11.004.

Chen, G.D., Li, H.B., Wei, Y.M., Zheng, Y.L., Zhou, M.X., and Liu, C.J. (2016). Pleiotropic effects of the semi-dwarfing gene $u z u$ in barley. Euphytica 209(3), 749-755. doi: 10.1007/s10681-016-1668-4.

Chen, G.D., Li, H.B., Zheng, Z., Wei, Y.M., Zheng, Y.L., McIntyre, C.L., Zhou, M.X., and Liu, C.J. (2012). Characterization of a QTL affecting spike morphology on the long arm of chromosome $3 \mathrm{H}$ in barley (Hordeum vulgare L.) based on near isogenic lines and a NILderived population. Theoretical and Applied Genetics 125(7), 1385-1392. doi: 10.1007/s00122-012-1918-3.

Do, T.H.T., Martinoia, E., and Lee, Y. (2018). Functions of ABC transporters in plant growth and development. Current Opinion in Plant Biology 41, 32-38.

Duan, P., Rao, Y., Zeng, D., Yang, Y., Xu, R., Zhang, B., Dong, G., Qian, Q., and Li, Y. (2014). SMALL GRAIN 1, which encodes a mitogen - activated protein kinase kinase 4, influences grain size in rice. The Plant Journal 77(4), 547-557.

Fan, C., Xing, Y., Mao, H., Lu, T., Han, B., Xu, C., Li, X., and Zhang, Q. (2006). GS3, a major QTL for grain length and weight and minor QTL for grain width and thickness in rice, encodes a putative transmembrane protein. Theoretical and Applied Genetics 112(6), 11641171.

Fang, Z., Ji, Y., Hu, J., Guo, R., Sun, S., and Wang, X. (2020). Strigolactones and brassinosteroids antagonistically regulate the stability of the D53-OsBZR1 complex to determine FC1 expression in rice tillering. Molecular Plant 13(4), 586-597.

Giraldo, P., Benavente, E., Manzano-Agugliaro, F., and Gimenez, E. (2019). Worldwide Research Trends on Wheat and Barley: A Bibliometric Comparative Analysis. Agronomy 9(7), 352.

Hadjichristodoulou, A. (1990). Stability of 1000-grain weight and its relation with other traits of barley in dry areas. Euphytica 51(1), 11-17.

Holopainen, U.R., Wilhelmson, A., Salmenkallio-Marttila, M., Peltonen-Sainio, P., Rajala, A., Reinikainen, P., Kotaviita, E., Simolin, H., and Home, S. (2005). Endosperm structure affects the malting quality of barley (Hordeum vulgare L.). Journal of Agricultural and Food Chemistry 53(18), 7279-7287. 
Ishimaru, K., Hirotsu, N., Madoka, Y., Murakami, N., Hara, N., Onodera, H., Kashiwagi, H., Ujiie, K., Shimizu, B., Onishi, A., Miyagawa, H., and Katoh, E. (2013). Loss of function of the IAA-glucose hydrolase gene TGW6 enhances rice grain weight and increases yield. Nature Genetics 45(6), 707-711.

Lai, L.B., Nadeau, J.A., Lucas, J., Lee, E.-K., Nakagawa, T., Zhao, L., Geisler, M., and Sack, F.D. (2005). The Arabidopsis R2R3 MYB proteins FOUR LIPS and MYB88 restrict divisions late in the stomatal cell lineage. The Plant Cell 17(10), 2754-2767.

Larsen, P.B., Cancel, J., Rounds, M., and Ochoa, V. (2007). Arabidopsis ALS1 encodes a root tip and stele localized half type $\mathrm{ABC}$ transporter required for root growth in an aluminum toxic environment. Planta 225(6), 1447.

Li, H., Chen, G., and Yan, W. (2015). Molecular characterization of barley 3H semi-dwarf genes. PLoS One 10(3).

Li, Y., Fan, C., Xing, Y., Jiang, Y., Luo, L., Sun, L., Shao, D., Xu, C., Li, X., Xiao, J., He, Y., and Zhang, Q. (2011). Natural variation in GS5 plays an important role in regulating grain size and yield in rice. Nature Genetics 43(12), 1266-1269.

Liu, L., Tong, H., Xiao, Y., Che, R., Xu, F., Hu, B., Liang, C., Chu, J., Li, J., and Chu, C. (2015a). Activation of Big Grain1 significantly improves grain size by regulating auxin transport in rice. Proceedings of the National Academy of Sciences 112(35), 11102-11107.

Liu, S., Hua, L., Dong, S., Chen, H., Zhu, X., Jiang, J., Zhang, F., Li, Y., Fang, X., and Chen, F. (2015b). Os MAPK 6, a mitogen - activated protein kinase, influences rice grain size and biomass production. The Plant Journal 84(4), 672-681.

Ma, B., He, S.-J., Duan, K.-X., Yin, C.-C., Chen, H., Yang, C., Xiong, Q., Song, Q., Lu, Q., Chen, H., Zhang, Q., Lu, T., Chen, S., and Zhang, J. (2013). Identification of rice ethyleneresponse mutants and characterization of MHZ7/OsEIN2 in distinct ethylene response and yield trait regulation. Molecular Plant 6(6), 1830-1848.

Ma X, Feng F, Zhang Y, Elesawi IE, Xu K, Li T, Mei H, Liu H, Gao N, Chen C.(2019). A novel rice grain size gene OsSNB was identified by genome-wide association study in natural population. PLoS genetics 15, e1008191.

Mao, H., Sun, S., Yao, J., Wang, C., Yu, S., Xu, C., Li, X., and Zhang, Q. (2010). Linking differential domain functions of the GS3 protein to natural variation of grain size in rice. Proceedings of the National Academy of Sciences 107(45), 19579-19584.

Mascher, M., Muehlbauer, G.J., Rokhsar, D.S., Chapman, J., Schmutz, J., Barry, K., MuñozAmatriaín, M., Close, T., Wise, R., Schulman, A., Himmelbach, A., Mayer, X., Scholz, U., Poland, J., Stein, N., and Waugh, R. (2013). Anchoring and ordering NGS contig assemblies by population sequencing (POPSEQ). The Plant Journal 76(4), 718-727.

Mayolle, J., Lullien-Pellerin, V., Corbineau, F., Boivin, P., and Guillard, V. (2012). Water diffusion and enzyme activities during malting of barley grains: a relationship assessment. Journal of Food Engineering 109(3), 358-365.

Næsted, H., Holm, A., Jenkins, T., Nielsen, H.B., Harris, C.A., Beale, M.H., Andersen, M., Mant, A., Scheller, H., Camara, B., Mattsson, O., and Mundy, J. (2004). Arabidopsis 
VARIEGATED 3 encodes a chloroplast-targeted, zinc-finger protein required for chloroplast and palisade cell development. Journal of Cell Science 117(20), 4807-4818.

Peltonen-Sainio, P., Kangas, A., Salo, Y., and Jauhiainen, L. (2007). Grain number dominates grain weight in temperate cereal yield determination: evidence based on 30 years of multilocation trials. Field Crops Research 100(2-3), 179-188.

Psota, V., Vejražka, K., Faměra, O., and Hrčka, M. (2007). Relationship between grain hardness and malting quality of barley (Hordeum vulgare L.). Journal of the Institute of Brewing 113(1), 80-86.

Pu, L., Li, Q., Fan, X., Yang, W., and Xue, Y. (2008). The R2R3 MYB transcription factor GhMYB109 is required for cotton fiber development. Genetics 180(2), 811-820.

Qi, P., Lin, Y.-S., Song, X.-J., Shen, J.-B., Huang, W., Shan, J.-X., Zhu, M., Jiang, L., Gao, J., and Lin, H. (2012). The novel quantitative trait locus GL3. 1 controls rice grain size and yield by regulating Cyclin-T1; 3. Cell Research 22(12), 1666-1680.

Rotman, N., Durbarry, A., Wardle, A., Yang, W.C., Chaboud, A., Faure, J.-E., Berger, F., and Twell, D. (2005). A novel class of MYB factors controls sperm-cell formation in plants. Current Biology 15(3), 244-248.

Serrago, R.A., Alzueta, I., Savin, R., and Slafer, G.A. (2013). Understanding grain yield responses to source-sink ratios during grain filling in wheat and barley under contrasting environments. Field Crops Research 150, 42-51.

Shi, C.L., Dong, N.Q., Guo, T., Ye, W.W., Shan, J.X., and Lin, H.X. (2020). A quantitative trait locus GW6 controls rice grain size and yield through the gibberellin pathway. The Plant Journal.

Stein, N., Herren, G., and Keller, B. (2001). A new DNA extraction method for high - throughput marker analysis in a large - genome species such as Triticum aestivum. Plant Breeding 120(4), 354-356.

Sun, L., Ma, D., Yu, H., Zhou, F., Li, Y., Luo, L., Gao, G., Zhang, Q., Xu, C., and He, Y. (2013). Identification of quantitative trait loci for grain size and the contributions of major grainsize QTLs to grain weight in rice. Molecular Breeding 31(2), 451-461.

Tao Y, Zhao X, Wang X, Hathorn A, Hunt C, Cruickshank AW, van Oosterom EJ, Godwin ID, Mace ES, Jordan DR. (2020). Large-scale GWAS in sorghum reveals common genetic control of grain size among cereals. Plant biotechnology journal 18, 1093-1105.

Tian, Y., Zhang, M., Hu, X., Wang, L., Dai, J., Xu, Y., and Chen, F. (2016). Over-expression of CYP78A98, a cytochrome P450 gene from Jatropha curcas L., increases seed size of transgenic tobacco. Electronic Journal of Biotechnology 19, 15-22.

von Korff, M., Wang, H., Léon, J., and Pillen, K. (2008). AB-QTL analysis in spring barley: III. Identification of exotic alleles for the improvement of malting quality in spring barley $(H$. vulgare ssp. spontaneum). Molecular Breeding 21(1), 81-93.

Voorrips, R. (2002). MapChart: software for the graphical presentation of linkage maps and QTLs. Journal of Heredity 93(1), 77-78. 
Walker, C.K., Ford, R., Muñoz-Amatriaín, M., and Panozzo, J.F. (2013). The detection of QTLs in barley associated with endosperm hardness, grain density, grain size and malting quality using rapid phenotyping tools. Theoretical and Applied Genetics 126(10), 2533-2551.

Walker, C.K., and Panozzo, J.F. (2016). Genetic characterisation, expression and association of quality traits and grain texture in barley (Hordeum vulgare L.). Euphytica 212(2), 157-171. doi: 10.1007/s10681-016-1767-2.

Wang, J., Wang, R., Mao, X., Zhang, J., Liu, Y., Xie, Q., Yang, X., Chang, X., Li, C., Zhang, X., and Jing, R. (2020). RING finger ubiquitin E3 ligase gene TaSDIR1-4A contributes to grain size in common wheat. Journal of Experimental Botany 71(18), 5377-5388, https://doi.org/10.1093/jxb/eraa271

Wang, J., Yang, J., McNeil, D.L., and Zhou, M. (2010). Identification and molecular mapping of a dwarfing gene in barley (Hordeum vulgare L.) and its correlation with other agronomic traits. Euphytica 175(3), 331-342. doi: 10.1007/S10681-010-0175-2.

Wang, J., Yang, J., Zhang, Q., Zhu, J., Jia, Q., Hua, W., Shang, Y., Li, C., and Zhou, M. (2015). Mapping a major QTL for malt extract of barley from a cross between TX9425× Naso Nijo. Theoretical and Applied Genetics 128(5), 943-952.

Wang, Q., Sun, G., Ren, X., Du, B., Cheng, Y., Wang, Y., Li, C., and Sun, D. (2019). Dissecting the Genetic Basis of Grain Size and Weight in Barley (Hordeum vulgare L.) by QTL and Comparative Genetic Analyses. Fronties in Plant Science 10, 469. doi: 10.3389/fpls.2019.00469.

Wang, S., Wu, K., Yuan, Q., Liu, X., Liu, Z., Lin, X., Zeng, R., Zhu, H., Dong, G., Qian, Q., Zhang, G., and Fu, X. (2012). Control of grain size, shape and quality by OsSPL16 in rice. Nature Genetics 44(8), 950.

Watt, C., Zhou, G., McFawn, L.A., Chalmers, K.J., and Li, C. (2019). Fine mapping of qGL5H, a major grain length locus in barley (Hordeum vulgare L.). Theoretical and Applied Genetics 132(4), 883-893. doi: 10.1007/s00122-018-3243-y.

Watt, C., Zhou, G., McFawn, L.A., and Li, C. (2020). Fine mapping qGL2H, a major locus controlling grain length in barley (Hordeum vulgare L.). Theoretical and Applied Genetics doi: 10.1007/s00122-020-03579-z.

Wendt, T., Holme, I., Dockter, C., Preuss, A., Thomas, W., Druka, A., Waugh, R., Hansson, M., and Braumann, I. (2016). HvDepl is a positive regulator of culm elongation and grain size in barley and impacts yield in an environment-dependent manner. PLoS One 11(12), e0168924. doi: 10.1371/journal.pone.0168924.

Xu, R., Wang, J., Li, C., Johnson, P., Lu, C., and Zhou, M. (2012). A single locus is responsible for salinity tolerance in a Chinese landrace barley (Hordeum vulgare L.). PLoS One 7(8), e43079. https://doi.org/10.1371/journal.pone.0043079

Xu, X., Sharma, R., Tondelli, A., Russell, J., Comadran, J., Schnaithmann, F., Pillen, K., Kilian, B., Cattivelli, L., Thomas, W., and Flavell, A. (2018). Genome-Wide Association Analysis of Grain Yield-Associated Traits in a Pan-European Barley Cultivar Collection. Plant Genome 11(1). doi: 10.3835/plantgenome2017.08.0073. 
459

460

461

462

463

464

465

466

467

468

469

470

471

472

473

474

475

476

477

478
Yu, W., Tan, X., Zou, W., Hu, Z., Fox, G.P., Gidley, M.J., and Gilbert, R. (2017). Relationships between protein content, starch molecular structure and grain size in barley. Carbohydrate Polymers 155, 271-279.

Zhang, H., Liang, W., Yang, X., Luo, X., Jiang, N., Ma, H., and Zhang, D. (2010). Carbon starved anther encodes a MYB domain protein that regulates sugar partitioning required for rice pollen development. The Plant Cell 22(3), 672-689.

Zhang, X., Wang, J., Huang, J., Lan, H., Wang, C., Yin, C., Wu, Y., Tang, H., Qian, Q., Li, Y., and Zhang, H. (2012). Rare allele of OSPPKL1 associated with grain length causes extralarge grain and a significant yield increase in rice. Proceedings of the National Academy of Sciences 109(52), 21534-21539.

Zhou, H., Liu, S., Liu, Y., Liu, Y., You, J., Deng, M., Ma, J., Chen, G., Wei, Y., Liu, C., and Zheng, Y. (2016). Mapping and validation of major quantitative trait loci for kernel length in wild barley (Hordeum vulgare ssp. spontaneum). BMC Genetics 17(1), 130. doi: 10.1186/s12863-016-0438-6.

Zhou, M.X. (2010). "Barley Production and Consumption," in Genetics and Improvement of Barley Malt Quality, eds. G. Zhang \& C. Li. (Berlin, Heidelberg: Springer Berlin Heidelberg), 1-17.

Zohary, D., Hopf, M., and Weiss, E. (2012). Domestication of Plants in the Old World: The origin and spread of domesticated plants in Southwest Asia, Europe, and the Mediterranean Basin. Oxford University Press on Demand. 


\section{Figure captions}

Figure 1 QTL associated with grain size in barley.

Figure 2 Grain length (left) and grain width (right) of near isogenic lines. The pair of NIL were selected from $\mathrm{F}_{8}$ recombinant inbred lines from the cross of TX9425 and Naso Nijo. The markers linked to malt extract was used to select heterozygous individuals and then selfed. Homozygous lines from the next generation $\left(\mathrm{F}_{9}\right)$ were selected as NIL pairs. These pairs were genotyped with high density markers and evaluated for malt extract. The pair we used here (one line with high malt extract and three lines with low malt extract) showed significant difference in malting quality and the whole genome marker screening showed only differences in the QTL region for malting extract (14 - $18 \mathrm{cM}$, Figure 1). 


\section{Figure 1}

QTL associated with grain size in barley.

QTL associated with grain size in barley.
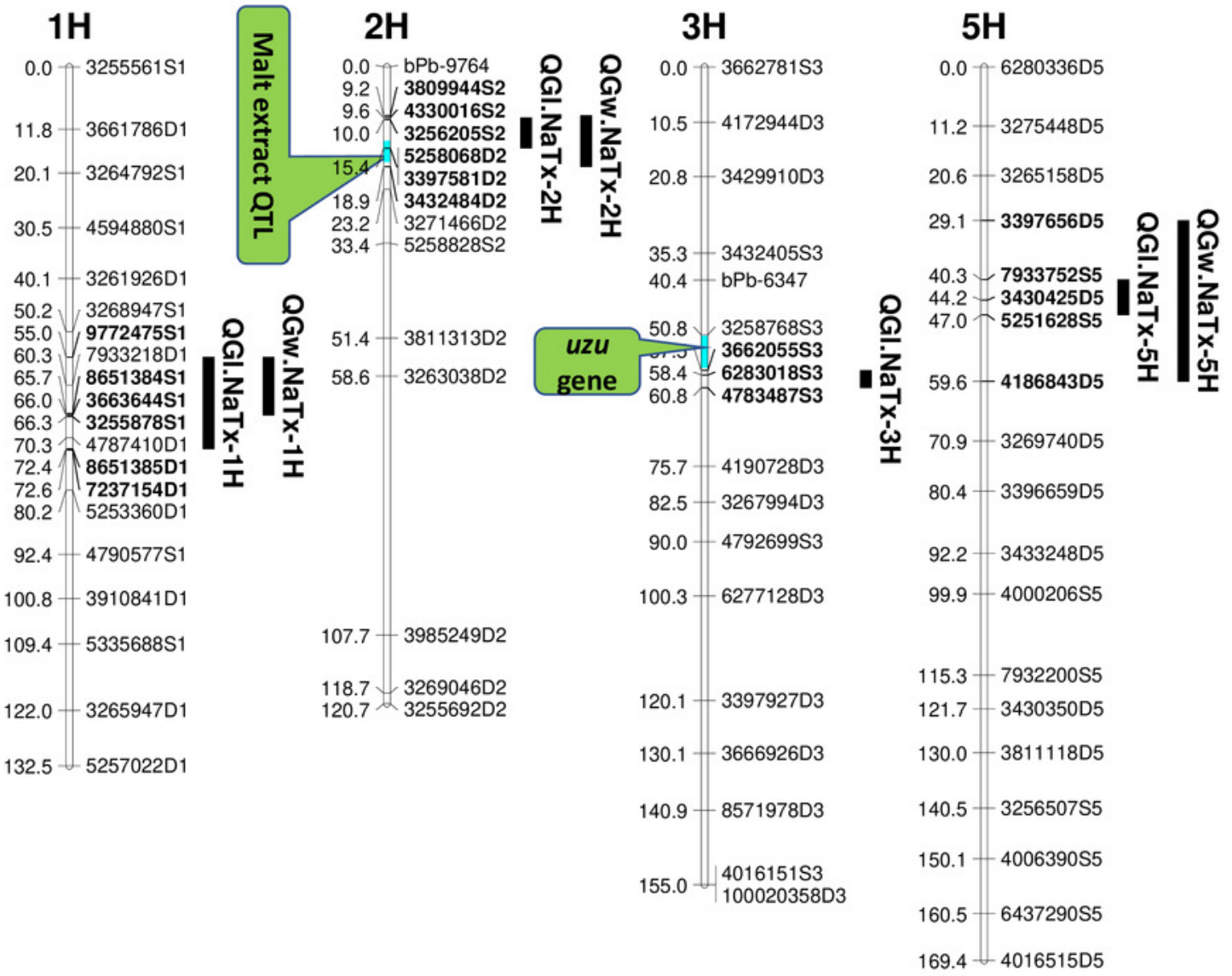


\section{Figure 2}

Grain length (left) and grain width (right) of near isogenic lines.

The pair of NIL were selected from $F_{8}$ recombinant inbred lines from the cross of TX9425 and Naso Nijo. The markers linked to malt extract was used to select heterozygous individuals and then selfed. Homozygous lines from the next generation $\left(F_{g}\right)$ were selected as NIL pairs. These pairs were genotyped with high density markers and evaluated for malt extract. The pair we used here (one line with high malt extract and three lines with low malt extract) showed significant difference in malting quality and the whole genome marker screening showed only differences in the QTL region for malting extract (14 - 18 cM, Figure 1). 


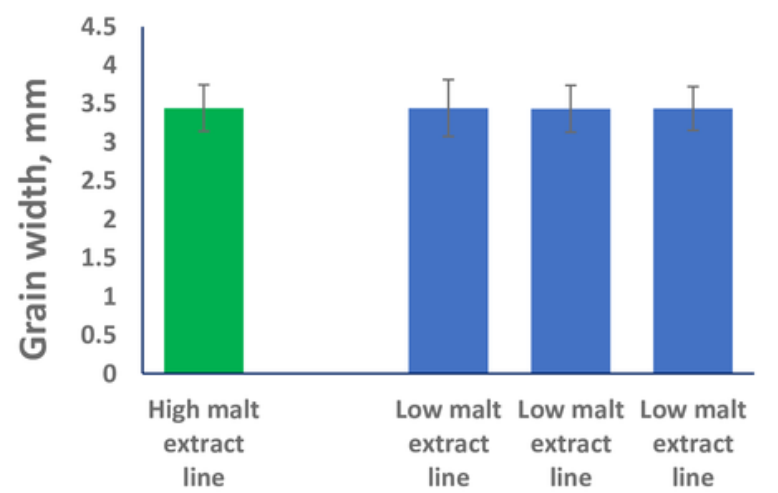

Near isogenic lines

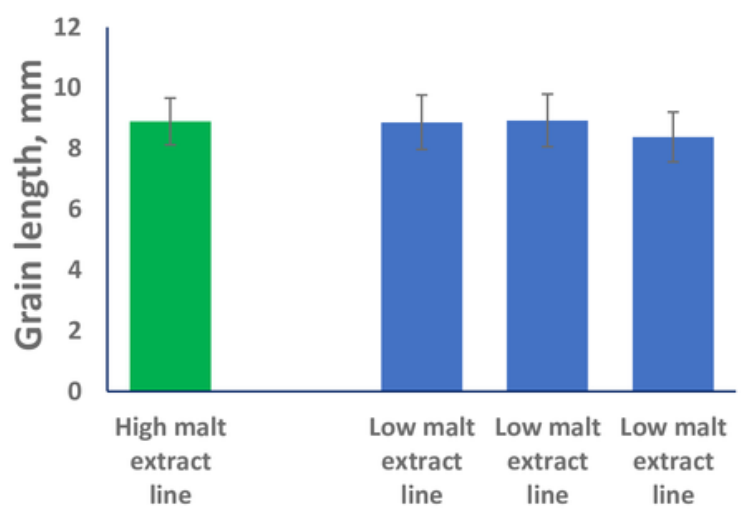

Near isogenic lines 


\section{Table 1 (on next page)}

Mean and range of grain size traits tested in different environments 
1 Table 1 Mean and range of grain size traits tested in different environments

\begin{tabular}{|c|c|c|c|c|c|}
\hline \multirow[t]{2}{*}{ Trait } & \multirow[t]{2}{*}{ Environment } & \multirow[t]{2}{*}{ TX } & \multirow[t]{2}{*}{$\mathbf{N N}$} & \multicolumn{2}{|c|}{ DH } \\
\hline & & & & $\operatorname{Mean} \pm$ SD & Range \\
\hline \multirow{8}{*}{$\begin{array}{l}\text { GL } \\
(\mathrm{mm})\end{array}$} & HZ07 & 8.14 & 7.87 & $8.16 \pm 0.22$ & $7.67-8.74$ \\
\hline & HZ08 & 8.42 & 8.07 & $8.43 \pm 0.26$ & $7.645-9.31$ \\
\hline & HZ11 & 8.43 & 8.14 & $8.58 \pm 0.25$ & $7.61-9.31$ \\
\hline & YC07 & 8.47 & 8.13 & $8.55 \pm 0.28$ & $7.71-9.29$ \\
\hline & YC08 & 8.54 & 8.23 & $8.68 \pm 0.27$ & $7.83-9.39$ \\
\hline & YC11 & 8.81 & 8.02 & $8.81 \pm 0.28$ & $7.81-9.46$ \\
\hline & BS07 & 8.73 & 8.51 & $8.79 \pm 0.28$ & $7.98-9.42$ \\
\hline & BS08 & 8.57 & 8.35 & $8.75 \pm 0.22$ & $8.01-9.3$ \\
\hline \multirow{8}{*}{$\begin{array}{l}\text { GW } \\
(\mathrm{mm})\end{array}$} & HZ07 & 3.72 & 3.82 & $3.79 \pm 0.08$ & $3.55-4.05$ \\
\hline & HZ08 & 3.56 & 3.73 & $3.66 \pm 0.08$ & $3.22-3.88$ \\
\hline & HZ11 & 3.68 & 3.75 & $3.71 \pm 0.09$ & $3.51-4.02$ \\
\hline & YC07 & 3.62 & 3.85 & $3.67 \pm 0.09$ & $3.42-3.96$ \\
\hline & YC08 & 3.64 & 3.83 & $3.7 \pm 0.08$ & $3.48-3.99$ \\
\hline & YC11 & 3.77 & 3.87 & $3.78 \pm 0.08$ & $3.57-4.02$ \\
\hline & BS07 & 3.65 & 3.76 & $3.72 \pm 0.08$ & $3.52-3.94$ \\
\hline & BS08 & 3.74 & 3.79 & $3.78 \pm 0.18$ & $3.49-4.13$ \\
\hline
\end{tabular}

2 SD: standard deviation; TX: a Chinese feed barley variety TX9425; NN: a Japanese malting barley variety Naso Nijo;

3 DH: double-haploid; GL: grain length; GW: grain width; HZ, YC, BS represent different locations (Hangzhou,

4 Yancheng and Baoshan, respectively) and the number after locations are the year of harvest. 
Table 2 (on next page)

Analysis of variance on grain size traits in DH population lines from Naso Nijo $\times$ TX9425 ( $F$ values) 
1 Table 2 Analysis of variance on grain size traits in DH population lines from Naso Nijo $\times$ 2 TX9425 (F values)

\begin{tabular}{lll}
\hline $\begin{array}{ll}\text { Source of } \\
\text { Variation }\end{array}$ & $\mathrm{GL}$ & $\mathrm{GW}$ \\
\hline Block & $8.136^{* *}$ & $3.0^{*}$ \\
Genotype(G) & $12.53^{* *}$ & $8.3^{* *}$ \\
Location(L) & $1215.95^{* *}$ & $186.89^{* *}$ \\
Year(Y) & $208.15^{* *}$ & $44.5^{* *}$ \\
Y $\times \mathrm{L}$ & $109.74^{* *}$ & $483.38^{* *}$ \\
$\mathrm{G} \times \mathrm{Y}$ & $1.53^{* *}$ & $2.11^{* *}$ \\
$\mathrm{G} \times \mathrm{L}$ & $1.59^{* *}$ & $2.39^{* *}$ \\
$\mathrm{G} \times \mathrm{L} \times \mathrm{Y}$ & $1.65^{* *}$ & $2.2^{* *}$ \\
\hline
\end{tabular}


Table 3 (on next page)

QTL for barley grain size traits in the DH population of Naso Nijo $\times$ TX9425 
Table 3 QTL for barley grain size traits in the DH population of Naso Nijo $\times$ TX9425

\begin{tabular}{|c|c|c|c|c|c|c|c|c|c|c|c|}
\hline $\begin{array}{l}\text { Tra } \\
\text { it }\end{array}$ & $\begin{array}{c}\text { Linka } \\
\text { ge } \\
\text { grou } \\
\text { p }\end{array}$ & $\begin{array}{c}\text { QTL } \\
\text { name }\end{array}$ & $\begin{array}{l}\text { Nearest } \\
\text { marker }\end{array}$ & $\begin{array}{c}\text { Positi } \\
\text { on } \\
\text { (cM) }\end{array}$ & $\begin{array}{l}\text { Two } \\
\text { LOD } \\
\text { suppo } \\
\text { rt } \\
\text { interv } \\
\text { als }\end{array}$ & $\begin{array}{l}\text { LO } \\
\text { D }\end{array}$ & $\begin{array}{c}R^{2} \\
(\% \\
)\end{array}$ & $\begin{array}{c}\text { Sourc } \\
\text { e of } \\
\text { positi } \\
\text { ve } \\
\text { effect }\end{array}$ & $\begin{array}{l}\text { Additi } \\
\text { ve } \\
\text { effect }\end{array}$ & $\begin{array}{l}\text { Malt } \\
\text { extract } \\
\text { as } \\
\text { covari } \\
\text { ate }\end{array}$ & $\begin{array}{c}\text { Uzu } \\
\text { Gene } \\
\text { as } \\
\text { covari } \\
\text { ate }\end{array}$ \\
\hline GL & $1 \mathrm{H}$ & $\begin{array}{c}\text { QGl.NaT } \\
x-1 H\end{array}$ & $\begin{array}{c}3255878 \\
\text { S1 }\end{array}$ & 66.29 & $\begin{array}{c}54.98- \\
72.38\end{array}$ & $\begin{array}{c}10.6 \\
4\end{array}$ & $\begin{array}{c}11 . \\
9\end{array}$ & NN & 0.073 & $\mathrm{NC}$ & $\mathrm{NC}$ \\
\hline & $2 \mathrm{H}$ & $\begin{array}{c}\text { QGl.NaT } \\
x-2 H\end{array}$ & $\begin{array}{c}3256205 \\
\text { S2 }\end{array}$ & 10.02 & $\begin{array}{l}9.56- \\
15.44\end{array}$ & $\begin{array}{c}21.9 \\
5\end{array}$ & $\begin{array}{c}29 . \\
8\end{array}$ & $\mathrm{TX}$ & -0.111 & 23.0 & $\mathrm{NC}$ \\
\hline & $3 \mathrm{H}$ & $\begin{array}{c}\text { QGI.NaT } \\
x-3 H\end{array}$ & $\begin{array}{c}6283018 \\
\text { S3 }\end{array}$ & 58.43 & $\begin{array}{c}57.51- \\
60.84\end{array}$ & $\begin{array}{c}17.4 \\
6\end{array}$ & $\begin{array}{c}21 . \\
9\end{array}$ & $\mathrm{NN}$ & 0.259 & $\mathrm{NC}$ & 11.6 \\
\hline & $5 \mathrm{H}$ & $\begin{array}{c}\text { QGl.NaT } \\
x-5 H\end{array}$ & $\begin{array}{c}3264393 \\
\text { S5 }\end{array}$ & 47.19 & $\begin{array}{c}40.34- \\
47.01\end{array}$ & 6.25 & 6.2 & $\mathrm{TX}$ & 0.044 & $\mathrm{NC}$ & $\mathrm{NC}$ \\
\hline GW & $1 \mathrm{H}$ & $\begin{array}{c}Q G w \cdot N a \\
T x-1 H\end{array}$ & $\begin{array}{c}4170979 \\
\text { D1 }\end{array}$ & 65.7 & $\begin{array}{c}54.98- \\
66.00\end{array}$ & 4.13 & 9.5 & NN & 0.02 & $\mathrm{NC}$ & $\mathrm{NC}$ \\
\hline & $2 \mathrm{H}$ & $\begin{array}{c}Q G w \cdot N a \\
T x-2 H\end{array}$ & $\begin{array}{c}5258068 \\
\text { D2 }\end{array}$ & 15.44 & $\begin{array}{l}9.24- \\
18.91\end{array}$ & 7.69 & $\begin{array}{c}18 . \\
5\end{array}$ & $\mathrm{TX}$ & -0.025 & 15.7 & $\mathrm{NC}$ \\
\hline & $5 \mathrm{H}$ & $\begin{array}{c}Q G w \cdot N a \\
T x-5 H\end{array}$ & $\begin{array}{c}3430425 \\
\text { D5 }\end{array}$ & 44.24 & $\begin{array}{c}29.10- \\
59.58\end{array}$ & 3.73 & 8.5 & $\mathrm{NN}$ & 0.018 & $\mathrm{NC}$ & NC \\
\hline
\end{tabular}

The position is that of the nearest marker; $\mathrm{R}^{2}$ means percentage genetic variance explained by the nearest marker; Two LOD support intervals were used to indicate the $95 \%$ confidence intervals (van Ooijen 1992); NC means no significant changes. 
